\title{
A CONDIÇÃO DO AMICUS CURIAE NO CONTROLE CONCENTRADO DE CONSTITUCIONALIDADE E O FILTRO A SUA PARTICIPAÇÃO NO MODELO DE ESTADO BRASILEIRO QUE SE PRETENDE DEMOCRÁTICO DE DIREITO
}

\section{Renato Horta Rezende ${ }^{1}$}

\section{RESUMO:}

O Estado Democrático de Direito e a pós-modernidade exigem que as decisões estatais estejam revestidas estruturalmente de validade democrática, entretanto, no controle concentrado de constitucionalidade, filtros restringem participações mesmo daqueles potencialmente atingidos pela decisão. Investigou-se, por meio da relação entre Direito e democracia, se as barreiras impostas à participação do amicus curiae no controle concentrado de constitucionalidade atentam contra o modelo de Estado brasileiro. O método de pesquisa aplicado foi o hipotético-dedutivo, partindo-se da hipótese de que a participação constitui elemento de validade estrutural do Estado Democrático de Direito indispensável ao modelo de Estado. A hipótese levantada foi confirmada.

Palavras-chaves: Amicus curiae; Estado Democrático de Direito; validade estrutural democrática; controle concentrado de constitucionalidade; sociedade aberta dos interpretes.

\section{THE CONDITION OF THE AMICUS CURIAE IN THE CONCENTRATED CONTROL OF CONSTITUTIONALITY AND THE FILTER TO ITS PARTICIPATION IN THE BRAZILIAN STATE MODEL THAT IS INTENDED TO BE DEMOCRATIC OF LAW}

\begin{abstract}
:
The Democratic State of Law and postmodernity require that state decisions should be structurally overlaid with democratic validity; however, in the concentrated control of constitutionality, filters restrict the participation of even those potentially affected by the decision. This research investigated whether the barriers imposed to the participation of the amicus curiae in the concentrated control of constitutionality attempt against the Brazilian State model. The applied research method was the hypothetic-deductive one, starting from the premise that the participation constitutes element of structural validity of the Democratic State of Law and its nonobservance against the model. The hypothesis raised was confirmed.
\end{abstract}

Keywords: Amicus curiae; Democratic State of Law; democratic structural validity; concentrated control of constitutionality; open society of interpreters.

\section{Introdução}

\footnotetext{
${ }^{1}$ Mestre em Direito pelo Programa de Pós-graduação em Direito da Universidade Fumec (2016); graduado em Direito pela Fundação Universidade de Itaúna (2004); Advogado inscrito na Seccional Minas Gerais (2005); Professor ministrando aulas de Direito Ambiental, Direito Previdenciário, Organizações e Normas Técnicas, Direito Minerário, Direito do Trabalho, Legislação profissional e ética no CEB-CECON (2007-2011); Direito Civil no CFDs da APMMG (2014); Arbitragem, mediação e conciliação junto ao Conselho Estadual de Arbitragem de Minas Gerais (2009-2017), Árbitro inscrito no CONFEJAB (2015); Estágio docência, ministrando aulas na disciplina metodologia de pesquisa jurídica na Faculdade de Direito da Universidade Fumec (2016); Especialização em ciência criminais na Faculdade Arnaldo Janssen (em andamento).
} 
A construção pluralista das escolhas decisórias estatais é o desafio enfrentado em um modelo de Estado que pretende constitucionalmente democrático de direito inserido na contemporaneidade formada por sociedades hipercomplexas e plurais.

A Constituição da República de 05 de outubro de 1988 se declarou constituída em modelo de Estado Democrático de Direito, exigindo como requisito a sustentar a validade das decisões estatais mais que a legalidade estrita, reivindicando que as escolhas decisórias sejam prescindidas de legitimidade democrática a estruturar e justificar facticidades impostas aos cidadãos.

A Constituição de 1988 e a Lei no 9868/99 arrolaram em rol taxativo aqueles que poderiam instar a Corte brasileira no controle de constitucionalidade, havendo ampliação dos legitimados em comparação ao ordenamento jurídico até então vigente, sendo, entretanto, reconhecido pelo próprio Supremo Tribunal Federal (STF), em seus julgados, o déficit democrático do procedimento ${ }^{2}$.

Diante do acima exposto buscou-se investigar se o filtro à participação do amicus curiae, regulado também ${ }^{3}$ no $\$ 2^{\circ}$ do art. $7^{\circ}$ da Lei 9868 , de 10 de novembro de 1999 , é adequado ao modelo de Estado brasileiro declarado no caput do art. $1^{\circ}$ da Constituição da República de 1988.

Identificado o problema partiu-se da hipótese segundo a qual, o atual momento histórico e filosófico, assim como o modelo de Estado Democrático de Direito exigem como meio a estruturar validamente decisões a ser proferida no controle concentrado de Constitucionalidade a participação efetiva daqueles potencialmente afetados, não como meio a legitimar escolhas, mas a conceber conformidade e coerência sistêmica democrática.

O desenvolvimento teórico e investigativo impresso na pesquisa utilizou o método científico hipotético-dedutivo, possuindo como referencial teórico a obra de Peter Häberle, "Hermenêutica constitucional a sociedade aberta dos interpretes da Constituição: contribuição para a interpretação pluralista e "procedimental' da Constituição".

A pesquisa foi construída em quatro partes, que coincidem com os objetivos específicos da pesquisa em que, na primeira, descreveremos as características da pósmodernidade, refletindo sobre as condições estruturantes do Estado Democrático de Direito;

\footnotetext{
${ }^{2}$ Cf: decisão monocrática em MC-ADI nº 5022, Brasília, 24 ago. 2013.

${ }^{3}$ Cf: RISTF.
} 
na parte seguinte são apresentados os contornos gerais da participação do amicus curiae nos Estados Unidos da América (EUA) e no Brasil, assim como a origem do termo; posteriormente empenharemos esforços a investigar a evolução jurídica do reconhecimento do amicus curiae no controle de constitucionalidade brasileiro; passando a última parte a dedicar-se ao estudo de adequação dos limites impostos à participação do amicus curiae no controle concentrado de constitucionalidade brasileiro frente ao modelo de Estado Democrático de Direito.

Para o desenvolvimento do trabalho foi realizado levantamento bibliográfico, da legislação pertinente e de decisões proferidas pelo STF, com a finalidade de contribuir para o desenvolvimento do raciocínio jurídico-científico sobre o tema.

\section{Interpretação constitucional da sociedade aberta como condição a estruturar validamente decisões judiciais no Estado Democrático de Direito}

Mergulhado no momento de incertezas e inseguranças contemporâneas, o Direito, instrumento do eixo regulatório estatal destinado a conter a racionalidade moral-prática, também se vê impactado, buscando apresentar fundamentos capazes de estruturalmente sustentar a legitimidade frente a sociedades e mercados plurais, hipercomplexos e desafiadores.

As atuais características sociais, destoantes das compreensões anteriores que deram origem a era Moderna, aglutinam-se às anomalias mercadológicas e jurídicas ampliando incertezas capazes de deflagrar desconformidade em virtude da inadequação da estrutura jurídica rígida construída sobre concepção social fictamente homogênea e horizontalizada, já não mais suficiente às exigências sociais desenvolvidas substancialmente em uma sociedade heterogenia e desigual.

O momento atual, pós-modernidade, não compreendido como novo paradigma, mas como momento de crise provocada por anomalias irresistíveis, reafirma o período de instabilidade por não ser capaz de apresentar qualquer proposição concreta e estável a superar aquilo que até então era posto, mas exige readequação dos pilares estatais, comunitários e mercadológico (HABERMAS, 1993, p. 102).

O controle de constitucionalidade desenvolvido frente à sociedade plural, pósModerna edificada sobre o modelo de Estado que se pretenda democrático de Direito, exige 
decisões proferidas em ambiente público e aberto aos argumentos trazidos por atores, direta e indiretamente, atingidos pela decisão, seja ela política ou jurídica.

Por sua vez, as decisões judiciais a serem proferidas em meio ao controle de constitucionalidade, não podem escapar à condição imposta pelo modelo de Estado devendo conservar aptidão capaz de acolher a integração dos intérpretes, para que assim, tanto a construção como a avaliação jurisdicional constitucional, estabeleçam-se de forma aberta à pluralidade democrática e mantendo a coerência com toda estrutura de validade imposta por um Estado que se pretenda democrático de Direito.

A necessidade da ampliação participativa tem como objetivo a concretização do modelo de Estado Democrático de Direito em sua concepção forte para que cada indivíduo, ao sentir-se coparticipe da construção dos sentidos constitucionais, reforce e renove seus vínculos com a permanência e a força sistêmica e coerente frente à Constituição (SAMPAIO, 2013, p. 436).

O processo imposto ao controle concentrado de constitucionalidade restrito a rol taxativo evidencia o déficit democrático do processo ao qual o STF reconhece e, por vezes, busca superar como é possível nas palavras do Ministro Celso de Mello:

Valioso, a propósito dessa particular questão, o magistério expendido pelo eminente Ministro GILMAR MENDES ("Direitos Fundamentais e Controle de Constitucionalidade", p. 503/504, $2^{\text {a }}$ ed., 1999, Celso Bastos Editor), em passagem na qual põe em destaque o entendimento de PETER HÄBERLE, para quem o Tribunal "há de desempenhar um papel de intermediário ou de mediador entre as diferentes forças com legitimação no processo constitucional" (p. 498), em ordem a pluralizar, em abordagem que deriva da abertura material da Constituição, o próprio debate em torno da controvérsia constitucional, conferindo-se, desse modo, expressão real e efetiva ao princípio democrático, sob pena de se instaurar, no âmbito do controle normativo abstrato, um indesejável "deficit" de legitimidade das decisões que o Supremo Tribunal Federal venha a pronunciar no exercício, "in abstracto", dos poderes inerentes à jurisdição constitucional (MELLO, 2013, p. 1, grifos do autor).

Destaca-se, desde logo, que se reconhece a diferença entre o poder de conformação amplo de que dispõe o legislador ordinário, enquanto intérprete da Constituição, e o espaço limitado a bases argumentativas de índole técnica, que se assegura ao juiz no exercício da interpretação constitucional, porém isto não significa haver divergências fundamentais a justificar o isolamento judicial, quando da interpretação constitucional, não sendo razoável e tampouco lógico admitir a avaliação com potencial modificativo de decisão democrática por ações que possuam déficit de legitimidade, contrária ao modelo de Estado declarado pela Constituição. 


\section{A condição do amicus curiae no controle concentrado de constitucionalidade e o filtro a sua participação no modelo de estado brasileiro que se pretende democrático de direito}

Destaca-se que o reconhecimento de uma comunidade de intérpretes da Constituição não tem o condão de limitar o Judiciário, porém objetiva contrariar orientações positivas e tecnicistas acerca da subsunção do fato à norma, reconhecendo alternativas em um processo aberto e ativo de compreensão constitucional pluralista e pós-positivista convergente com a realidade social e constitucional contemporânea (HÄBERLE, 2002, p. 30).

Häberle (2002, p. 31-32) observa que a legitimação democrática mediante simples participação formal no procedimento de interpretação constitucional realizada por juízes constitucionais de forma passiva, não se faz suficiente, sendo indispensável a abertura substancial de mão dupla, em que, tanto intérpretes não judiciais como judiciais aprendam mutuamente.

A abertura a influenciar a decisão jurisdicional de forma ampla e formalizada, assim como informal dirigida ao controle de constitucionalidade não afasta a independência do Judiciário, a liberdade pessoal e funcional do juiz constitucional necessária ao julgamento, isto porque a interpretação judicial dá-se na esfera pública realista, em que a Constituição organiza não apenas o Estado, mas a própria sociedade e setores da vida privada, estando assim sujeitos à análise ampla (HÄBERLE, 2002, p. 31).

A admissão à abertura da interpretação no processo de controle de constitucionalidade, além de juridicamente desejada, pois todo aquele que vive a Constituição é também seu legítimo intérprete, não sendo restrita a leitura a grupos específicos, inexistindo, no mundo real, o monopólio da interpretação (HÄBERLE, 2002, p. 13-15) formalmente atribuído à Suprema Corte ou ainda àqueles legitimados a instar a Corte no controle objetivo.

Em um modelo de Estado que se pretende democrático de Direito, como o brasileiro, a "democratização da interpretação constitucional” (HÄBERLE, 2002, p. 14) deve restar garantida justamente em face do direito fundamental à construção participativa das decisões públicas e do princípio da coisa pública, devendo existir espaço para os atores estatais e sociais eventualmente atingidos pela decisão participarem dos acordos sobre a interpretação normativa.

A abertura ao diálogo, de forma plural, tolerante e democrática, tem como objetivo alcançar a finalidade constitucional dirigida a estabilizar e integrar sociedade e Estado, trazendo unidade, ainda que inserida em conflitos, tensões e antagonismos, à qual a Constituição não está imune (CANOTILHO, 2003, p. 78).

O objetivo acima descrito repercute no compromisso de efetivação da Constituição, 
independentemente de qualquer vinculação ou devoção aos agentes do Estado-Juiz, tratandose a abertura da interpretação de um projeto cultural e não de um simples objeto pertencente ao Estado (SAMPAIO, 2013, p. 436).

Nesse mesmo sentido, “ela [a Constituição] não é, porém, apenas o espelho. Ela é, se se permite uma metáfora, a própria fonte de luz (Sie ist auch die Lichtquelle). Ela tem, portanto, uma função diretiva eminente" (HÄBERLE 2002, p. 34).

A pretensão constitucional de representar o desenvolvimento cultural a transforma, também, em um projeto normativo do Estado e da sociedade, que intensifica as contradições que afloram entre ambos e exige a adoção de hermenêutica constitucional adequada (CANOTILHO, 2003, p. 78-79).

A teoria da interpretação constitucional desenvolvida na modernidade esteve dirigida à sociedade fictamente planificada, concentrada, primariamente, na interpretação constitucional ofertada por juízes e na análise de vícios, exclusivamente, formais ${ }^{4}$ enfrentadas pelos Tribunais constitucionais (HÄBERLE, 2002, p. 12).

A racionalidade e a hipercomplexibilidade social desenvolvida na pós-modernidade, o movimento neoconstitucionalista que atribuiu normatividade e efetividade ao texto constitucional, e a instituição do modelo de Estado Democrático de Direito em que as decisões públicas necessitam da participação para que se estruturem legitimamente exigem alternativas à teoria da interpretação constitucional com a finalidade de efetivar direitos constitucionais de forma democrática.

A estrutura dinâmica e a ampliação dos direitos fundamentais apontam para a necessidade de aberturas à interpretação constitucional, afastando a eventual e excessiva rigidez interpretativa promovendo a adequação temporal da Constituição diante da intensidade, agilidade e dinamismo social atual (CANOTILHO, 2003, p. 78).

Diante da ampla normatividade constitucional, não restrita apenas à organização do Estado, mas amplamente estabelecida, o processo de interpretação constitucional passou a vincular "todos os órgãos estatais, todas as potências públicas, todos os cidadãos e grupos, não sendo possível estabelecer-se um elenco cerrado ou fechado com numerus clausus de intérpretes da Constituição" (HÄBERLE, 2002, p. 13).

\footnotetext{
${ }^{4}$ Cf: Costa e Benvindo (2013), assim como Renato Horta et al (2016) observam que as decisões proferidas pelo STF, entre os períodos de 1988 a 2015, dirigidas ao controle concentrado de constitucionalidade pouco analisam questões relacionadas a direitos fundamentais, estando as decisões concentradas em assuntos relacionados a vícios formais.
} 


\section{A condição do amicus curiae no controle concentrado de constitucionalidade e o filtro a sua participação no modelo de estado brasileiro que se pretende democrático de direito}

Nesse sentido, se a todos é dirigida a normatividade constitucional, é forçoso admitir que a todos também seja concedida possibilidade de interpretar formalmente o texto fundamental, pois, inicialmente, somente é possível cumprir determinações que se conheça, valendo destacar que a vontade em cumprir as disposições constitucionais é algo indispensável, pois a norma constitucional, diferente de outros ramos do direito, não sustenta instrumentos repressivos ou sancionatórios a incentivar o cumprimento (CANOTILHO, 2003, p. 78).

Outra inferência que desde logo é possível fazer corresponde à função proporcionalmente direta entre a hermenêutica constitucional e a pluralidade social, isto porque quanto mais pluralista for a sociedade, mais abertos devem ser os critérios e métodos de interpretação constitucional (HÄBERLE, 2002, p. 13), com a finalidade de incluir todas as perspectivas capazes de influenciar o sentido final atribuído ao texto constitucional.

Nessa perspectiva alargada, tem-se que a interpretação direcionada à Constituição é sempre consciente e intencional, podendo se dar de forma antecipada pelos atores sociais e estatais não jurídicos, ou/e final por atores jurídicos influenciados pelas interpretações pluralistas.

Consciente da subsistência da competência atribuída ao Judiciário para apresentar a adequada interpretação constitucional, Peter Häberle (2002, p. 20-23) explicita catálogo sistemático e amplo de participantes a influenciar formalmente e informalmente à hermenêutica jurídica constitucional.

O referido catálogo classifica tanto as funções estatais, como outros órgãos não estatais, a opinião pública e os autores constitucionalistas, atribuindo a todos a capacidade endógena de influenciar a interpretação constitucional final a ser proferida pelo Judiciário, tanto de maneira informal como formal, este último, por meio de instrumentos processuais.

O exercício interpretativo da Constituição se constitui de atividade que, potencialmente, diz respeito a todos, assim grupos estatais e não estatais e o próprio indivíduo podem ser considerados intérpretes constitucionais indiretos ou a longo prazo (HÄBERLE, 2002, p. 24).

A vasta gama de intérpretes da Constituição e a dinâmica social, cultural e moral exigem adequação da hermenêutica jurisdicional dirigida à Constituição, não sendo mais suficiente a conservação da ideia de que o processo de interpretação constitucional está reduzido aos órgãos estatais ou aos participantes diretos do processo de forma isolada 
(HÄBERLE, 2002, p. 24), como peregrinos a guiar-nos pela escuridão com a única tocha iluminadora.

Não se deve olvidar que as normas constitucionais gozam de relevante abertura semântica superior àquelas encontradas nas normas jurídicas ordinárias, exigindo sempre análise acerca da extensão de seu sentido, razão pela qual necessita de processo de concretização diferenciado, ainda que isto sobrecarregue o intérprete ${ }^{5}$ (SAMPAIO, 2013, p. 439).

Reconhecido o compartilhamento amplo da interpretação da Constituição, afastando a concepção de exclusividade e isolamento do juiz constitucional, exige em contrapartida acentuada ampliação das formas de participação que poderá se dar tanto em momento anterior $^{6}$ à judicialização como em seu trâmite junto ao Tribunal, vindicando, em todo caso, que o julgador, de forma livre, apresente a sua interpretação em correspondência com a atualização pública (HÄBERLE, 2002, p. 41).

A atualização como critério hermenêutico à interpretação judicial insere o tempo como elemento indispensável à interpretação, atribuindo condição infinita à atividade interpretativa, concebendo-a de forma contínua e dinâmica, conservando o mínimo indispensável para manter a função integrativa da Constituição.

O método de interpretação constitucional atinente à investigação de conteúdo e princípios que objetive a preservação de significados deve também disciplinar e canalizar as múltiplas formas de influência exercidas por diferentes participantes do processo, pois também determinantes para que se alcance a semântica normativa atual.

A criação, ampliação e aperfeiçoamento dos instrumentos de informação dos juízes constitucionais provenientes das formas gradativas de participação no processo constitucional

\footnotetext{
${ }^{5}$ Analisando acerca da especificidade da interpretação constitucional, Sampaio (2013, p. 438 e 439) observa que existem três posições acerca da necessidade ou não de hermenêutica diferenciada a ser aplicada ao texto constitucional, sendo elas: negativa, positiva e intermediária. Sinteticamente, a corrente negativa justifica-se na natureza normativa presente tanto na Constituição como nas leis ordinárias, não havendo assim motivo para tratamento desigual; a corrente positiva compreende que o texto constitucional exige maior esforço interpretativo por apresentar programas de realização progressiva e, a última corrente, intermediária, sustenta que, em regra, dever-se-ia utilizar a concepção negativa, porém, em se tratando de direitos fundamentais, de forma excepcional, deve prevalecer a corrente positiva. Nesta pesquisa, adotou-se o posicionamento positivo, o qual se acredita também ser a posição do citado autor.

${ }^{6}$ Häberle (2002, p. 42) observa que muitas questões de ordem constitucional material não são levadas à Suprema Corte, apontando duas prováveis razões para tanto, a incompetência da Corte e a falta de iniciativa dos interessados, concluindo que a interpretação constitucional de cunho material dá-se, principalmente, fora do Judiciário, de maneira autônoma pelos intérpretes em sentido amplo. Nas pesquisas realizadas por Renato Horta et al. (2016), assim como Costa e Benvindo (2013), é possível observar que, também no Brasil, poucos são os julgados proferidos pelo STF, em sede de controle concentrado de constitucionalidade, em que são avaliados direitos materiais.
} 
constituem-se em meio de representação da sociedade pluralista no processo constitucional (HÄBERLE, 2002, p. 46-47) o tornando adequado às expectativas sociais e o revestindo de legitimidade a estruturar as escolhas estatais.

A postura mais elástica e ampliativa concedida aos intérpretes pela Suprema Corte, quando materialmente exercida, além de apropriado ao momento pós-Moderno, ao movimento neoconstitucionalista e à filosofia pós-positivista jurídica, também constitui condição básica para assegurar a pretendida legitimação da jurisdição constitucional no modelo de Estado Democrático de Direito pretendido como meio a estruturar validamente as decisões estatais.

Contudo, a participação ampla dos interessados nas decisões a serem proferidas nas Cortes constitucionais exige, além do reconhecimento da sociedade aberta dos interpretes, também instrumentos processuais a efetivar a apresentação de concepções alternativas à interpretação constitucional.

3 Origem e contornos gerais da participação do amicus curiae nos EUA e Brasil inseridos no controle concentrado de constitucionalidade

A origem do termo amicus curiae (amigo da Corte) comporta infindáveis controvérsias que se relacionam com a concepção atribuída à própria expressão.

Para aqueles que atribuem ao amicus curiae perfil, absolutamente, neutro, caracterizando-o como um terceiro desinteressado cujo objetivo da atuação seria ajudar a Corte a evitar erros, agindo guiado por sua consciência, honra e integridade, a origem do termo residiria nas funções exercidas pelos consilliarius romanos, estando limitada às contribuições a argumentos jurídicos e somente participando do processo judicial quando autorizados pela Corte (MEDINA, 2010, p. 36).

$\mathrm{Na}$ ADI n 2130-MC, o relator, ministro Celso de Mello, argumentou que a intervenção do amicus curiae, para ser considerada legítima, deve apoiar-se em razões que o tornem desejável e útil a sua atuação processual na causa com o objetivo de proporcionar meios que viabilizem uma adequada resolução da divergência sobre os termos constitucionais, não defendendo qualquer interesse pessoal ou de terceiros (MELLO, 2013).

Para Damares Medina (2010, p. 79) a função do amicus curiae deve se restringir a informações e, justamente por essa razão, não é dado a este recorrer, exceto quando se tratar 
de erros crassos, ou evidências supervenientes e demais casos análogos que fujam ao exame da Corte, quando poderá atuar em nome da amizade, orientado pela sua função informacional e intuito de auxiliar a Corte.

Entretanto, para os que questionam a neutralidade e atribuem viés partidário e litigante, litigaring amicus, próximo das ações praticadas pela advocacia, a origem do amicus curiae seria a Inglaterra medieval, quando procedimentos possibilitaram ao interessado solicitar participação no processo judicial em que não é parte com a finalidade de colaborar com um dos litigantes, defendendo de forma reflexa interesse próprio, sem, contudo, deixar de auxiliar a $\operatorname{Corte}^{7}$ (MEDINA, 2010, p. 37-38).

Observa Weber $(2012$, p. 2) que a concepção inglesa orientou o desenvolvimento do instituto nos Estados Unidos (EUA):

Com base nessa noção, a Supreme Court dos Estados Unidos chega a negar a atuação de amicus curiae quando o postulante não esteja interessado em algum outro processo que será afetado pela decisão ou em suprir eventual deficiência de representação da parte com que almeja colaborar.

Segundo o art. 37.2 e art. 37.3 do regimento interno da Suprema Corte norteamericana é indispensável àquele que pretenda funcionar como amigo da Corte a demonstração de interesse próprio na conclusão judicial, seja ele direto ou indireto.

Apesar da semelhança inglesa, nos EUA participação dos amici curiae não nasceu do desejo da Corte em inserir um terceiro capaz de lhe auxiliar como na Inglaterra, mas da manifestação dos próprios litigantes norte-americanos que questionavam a impropriedade da aplicação de precedentes destoantes por sua Corte.

Os litigantes norte-americanos asseveravam que, em algumas situações, os precedentes aplicados pela Corte não apresentavam relação com os casos concretos que estavam sendo julgados, não sendo suficientemente amplos para alcançar as peculiaridades dos casos levados à Suprema Corte, o que tornava a aplicabilidade de alguns precedentes equivocada ou inadequada (CARVALHO, 2012, p. 8834), sendo necessário o auxílio de terceiros com a finalidade de contribuir no ajuste acertado da aplicação de precedentes.

A finalidade do exercício participativo dos amici curiae justificou a maior liberdade e atuação desses nos EUA, regulada no art. 37, após emenda, no regimento interno da Suprema Corte norte-americana (rule 37 of rules of U.S. supreme Court) (UNITED STATES OF AMERICA, 2013).

\footnotetext{
${ }^{7}$ Destaca Weber (2012, p. 1) que o instrumento de que dispunha o amicus era a apresentação de razões concisas e escritas, quando autorizada pela Corte.
} 
A integração dos amici curiae a funcionar na Corte constitucional norte-americana passou a exigir daqueles a declaração de interesse próprio no objeto da demanda, a autorização de alguma das partes ou o requerimento e acolhimento do Tribunal, sendo sua atividade ampla, como se parte originalmente fosse.

No Brasil, a exposição de motivos n ${ }^{\circ} 189$, de 7 de abril de 1997, que trata da Lei $n^{\circ}$ 9868/1999, reconhece explicitamente a inspiração norte-americana para regulação das atividades do amicus curiae no controle concentrado e abstrato de constitucionalidade brasileiro, conforme fragmento a seguir:

Constitui, todavia, inovação significativa a autorização para que outros titulares do
direito de propositura da ação direta possam manifestar-se, por escrito, sobre o
objeto da ação, pedir a juntada de documentos úteis para o exame da matéria no
prazo das informações, bem como apresentar memoriais (arts. $7^{\circ}, \S 1^{\circ}$, e $18, \S 1^{\circ}$ )
Trata-se de providência que confere um caráter pluralista ao processo objetivo de
controle abstrato de constitucionalidade, permitindo que o Tribunal decida com
pleno conhecimento dos diversos aspectos envolvidos na questão.
Da mesma forma, afigura-se digna de realce a proposta formulada com o sentido de
permitir que o relator, considerando a relevância da matéria e a representatividade
dos postulantes, admita a manifestação de outros órgãos ou entidades (arts. $7^{\circ}, \S 2^{\circ}$,
e $18, \S 2^{\circ}$ ). Positiva-se, assim, a figura do "amicus curiae" no processo de controle
de constitucionalidade, ensejando a possibilidade de o Tribunal decidir as causas
com pleno conhecimento de todas as suas implicações ou repercussões (BRASIL,
1997).

Próximo do conceito norte-americano, a expressão contemporânea de amicus curiae no Brasil assenta-se, sobretudo, na concepção de terceiro que, apesar de não ser parte no processo, está efetivamente interessado numa decisão favorável à interesses flagrantemente determináveis com os quais colabora e, para tanto, auxilia a Corte na conclusão que agasalhe também interesses próprios, reflexos por meio de perspectivas singulares de questões técnicas e/ou jurídicas (MEDINA, 2010, p. 43).

$\mathrm{O} \S 2^{\circ}$ do art. $7^{\circ}$ da Lei $n^{\circ} 9868 / 1999$ condiciona a participação do amicus curiae à significativa relevância da matéria e à demonstração de representação adequada, bem como à admissão pelo relator.

Assim, tem-se que a Lei $n^{\circ}$ 9868/1999 utilizou-se de pressupostos utilitaristas, segundo a qual a participação deve ser útil à Corte e ao mesmo tempo útil a todos os potenciais destinatários da decisão, inclusive ao próprio amicus curiae, contudo, a participação formal estaria condicionada à discricionariedade do ministro relator da ação judicial.

Esclarece-se, desde logo, que a lei não exige que as contribuições prestadas pelo amigo da Corte revelem-se inovadoras quanto aos termos da controversa, tampouco exige que 
o auxílio se dê, exclusivamente, no campo jurídico, entretanto a complexidade das relações e a interferência recíproca decorrente do entrelaçamento dos conjuntos normativos têm sido objeto de constantes posicionamentos e argumentos adotados pelos amici curiae (VALLE et $a l, 2012$, p. 45), algo importante para a ampliação do pluralismo jurídico interpretativo da Constituição.

A atuação do amicus curiae também não se assemelha a de perito judicial, que, apesar de auxiliar o juízo, tem como função principal empreender conhecimento técnico ou científico relativo à prova dos fatos. Da mesma forma, o amigo da Corte não se confunde com testemunha, não se subordinando aos atos das partes, tampouco está sujeito à exceção de suspeição ou compromisso.

O procedimento adotado pela Suprema Corte norte-americana para deferir a condição de amicus curiae ao requerente é relativamente divergente da adotada no Brasil, isto porque, como mencionado anteriormente, nos EUA caberá ao requerente apresentar o consentimento de pelo menos uma das partes envolvidas no litígio, inclusive se pretender fazer sustentação oral de seus argumentos, porém, independentemente do consentimento das partes litigantes, a Suprema Corte poderá admitir o ingresso do amigo da Corte no processo em virtude de seu poder discricionário e instrutório (UNITED STATES OF AMERICA, 2013).

No Brasil, o objetivo precípuo da participação do amicus curiae para funcionar na Suprema Corte consiste em pluralizar o debate constitucional e conferir maior coeficiente de legitimidade democrática aos julgamentos do STF (MELLO, 2012), enquanto nos EUA o objetivo consiste na defesa de interesses próprios e na aplicação adequada de precedentes.

Apesar do caráter mais privatista norte-americano em comparação com as motivações brasileiras, o procedimento adotado nos EUA concede maior oportunidade de ingresso que executado no Brasil, pois no primeiro, a participação do amicus curiae não está condicionada apenas à discricionariedade do relator, havendo alternativa, consubstanciada no consentimento de pelo menos uma das partes, algo que, no controle concentrado de constitucionalidade poderia ser substituído pelo consentimento de algum dos legitimados a que trata da Constituição de 1988 e a Lei no 9868/1999.

Apesar da via estreita acima delineada, no Brasil, o objetivo precípuo da participação do amigo da Corte no controle concentrado de constitucionalidade é colaborar com o Tribunal e pulverizar o debate constitucional conferindo maior coeficiente de legitimidade democrática 


\section{A condição do amicus curiae no controle concentrado de constitucionalidade e o filtro a sua participação no modelo de estado brasileiro que se pretende democrático de direito}

aos julgados (MELLO, 2012).

Diante dos objetivos direcionados à pluralidade e legitimidade, a participação do amicus curiae no Brasil não se resumem a relevância da matéria ou a aplicação adequada de antecedentes, mas antes de tudo, relaciona-se com a finalidade de se obter enfoques diversos dos construídos internamente, reconhecendo-se a pluralidade.

Portanto, não apenas o procedimento norte-americano de inserção do amigo da Corte no controle de constitucionalidade se difere do modelo brasileiro concentrado de constitucionalidade como também a sua finalidade.

Assim, o objetivo em conceder maior amplitude de participação ao amicus curiae ultrapassa a colheita das interpretações constitucionais e direciona-se principalmente à construção estrutural de validade da decisão, como enfatiza o ministro relator Celso de Mello em decisão monocrática proferida na Medida Cautelar em ADI n ${ }^{\circ} 5022$, quando afirma:

Não se pode perder de perspectiva que a intervenção processual do "amicus curiae"
tem por objetivo essencial pluralizar o debate constitucional, permitindo que o
Supremo Tribunal Federal venha a dispor de todos os elementos informativos
possíveis e necessários à resolução da controvérsia, visando-se, ainda, com tal
abertura procedimental, superar a grave questão pertinente à legitimidade
democrática das decisões emanadas desta Corte, quando no desempenho de seu
extraordinário poder de efetuar, em abstrato, o controle concentrado de
constitucionalidade, tal como destacam, em pronunciamento sobre o tema (MELLO,
2013, p. 4, grifo do autor).

Na decisão colacionada torna-se evidente a preocupação do Supremo Tribunal Federal em construir decisão de forma compartilhada, compreendendo haver pluralidade de interpretações sobre temas constitucionais, sendo indispensável à abertura procedimental para ser atribuída legitimidade substancial às conclusões judiciais.

\section{Evolução jurídica da participação do amicus curiae no controle concentrado de constitucionalidade no Brasil}

No Brasil, o amicus curiae passou a participar do controle objetivo de constitucionalidade $^{8}$ de maneira acanhada, casuística e informal, possuindo destaque a ADI $n^{\circ}$ 748, julgada em $1^{\text {o }}$ de maio de 1994, em que o relator, ministro Celso de Mello, admitiu a juntada, por linha, de memoriais preparados por terceiro que atuou como colaborador não

\footnotetext{
${ }^{8}$ Cumpre ressaltar que anterior à participação dos amici curiae no controle de constitucionalidade já havia na legislação pátria disciplina sobre o assunto, a saber: art. 32 da Lei no 4726, de 13 de julho de 1965, art. 31 da Lei $\mathrm{n}^{\circ}$ 6.385, de 7 de dezembro de 1976, art. 89 da Lei no 8884 , de 11 de junho de 1994.
} 
integrante da relação processual (VALLE et al, 2012, p. 41).

Depois desse fato, o instituto do amicus curiae continuou a evoluir casuisticamente no controle concentrado e abstrato de constitucionalidade, mesmo após a edição da Lei $\mathrm{n}^{\circ}$ 9868/1999, vindo, em 26 de novembro de 2003, no julgamento da ADI $n^{\circ} 2777$, a ser admitida a sustentação oral de amicus curiae pela maioria do Tribunal (STF, 2003).

Depois do pronunciamento, por maioria dos ministros do STF nos autos da referida ADI, foi então editada a Emenda Regimental, n 15, de 30 de março de 2004, que estendeu normativamente a possibilidade de sustentação oral também aos amici curiae de suas razões em tribuna, independentemente, de deferimento do relator, quando já admitido na condição de amicus e designada audiência pública.

A prerrogativa atribuída ao amigo da Corte pela Emenda Regimental inseriu-o definitiva e formalmente no universo das audiências públicas, tornando esta mais ampla, pois, além dos naturalmente envolvidos, legitimados, especialistas na matéria, autoridades, órgãos públicos, entidades representativas da sociedade civil e movimentos sociais, passam a contar também com os amici curiae (MELLO, 2015, s.p.).

A ampliação dos sujeitos aptos a participar das audiências públicas também como amigo da Corte, indubitavelmente, dá maior pluralização subjetiva ao processo de controle de constitucionalidade e vai ao encontro da busca pela legitimidade democrática a estruturar as decisões estatais proferidas em um Estado que se pretende Democrático de Direito (MORAES, 2011, p. 80).

A possibilidade de participação de audiência pública confere ao amicus curiae a oportunidade de se expressar oralmente, art. 154, parágrafo único, inciso $\mathrm{V}$ do Regimento interno do STF, fato que lhe concede maior visibilidade procedimental, política e social, atribuído à Suprema Corte o dever de atentar, formalmente, para as perspectivas apresentadas.

Porém, deve-se observar que o amigo da Corte, ainda que possua interesse direto no objeto da controversa constitucional, somente será admitido no controle normativo de constitucionalidade brasileiro quando representar, adequadamente, e de forma direta os interesses com os quais pretende colaborar, excluídos interesses reflexos ou, exclusivamente, pessoais, justamente em virtude do caráter objetivo do controle concentrado de constitucionalidade e a função informacional (MEDINA, 2012, p. 79), como já se manifestou o Supremo Tribunal Federal na ADPF no 46.

PROCESSO OBJETIVO - INTERVENÇÃO DE TERCEIRO EXCEPCIONALIDADE NÃO VERIFICADA - INDEFERIMENTO.1. Eis as 


\section{A condição do amicus curiae no controle concentrado de constitucionalidade e o filtro a sua participação no modelo de estado brasileiro que se pretende democrático de direito}

informações prestadas pelo Gabinete: A Federação Nacional dos Trabalhadores nas Empresas de Correios e Telégrafos e Similares - FENTECT requer que seja admitida, como amicus curiae, na arguição de descumprimento de preceito fundamental acima citado. Apresenta documentos. 2. É possível a aplicação, por analogia, ao processo revelador de arguição de descumprimento de preceito fundamental, da Lei $\mathrm{n}^{\mathbf{0}}$ 9.868/99, no que disciplina a intervenção de terceiro. Observe-se, no entanto, que a participação encerra exceção, consoante dispõe o artigo $7^{\circ}$ da referida lei, do seguinte teor: Art. $7^{\circ}$ Não se admitirá intervenção de terceiros no processo de ação direta de inconstitucionalidade. $\S 1^{\circ}$. $\S 2^{\circ} \mathrm{O}$ relator, considerando a relevância da matéria e a representatividade dos postulantes, poderá, por irrecorrível, admitir, observado o prazo fixado no parágrafo anterior, a manifestação de outros órgãos ou entidades. Está-se diante de arguição de descumprimento de preceito fundamental a envolver, em si, não os prestadores de serviços quer da Empresa Brasileira de Correios e Telégrafos - ECT, quer das demais empresas que são representadas pela arguente.3. Indefiro o pedido formulado. Devolva-se a peça à Federação requerente (AURÉLIO, 2003, s.p. , grifo nosso).

A exigência de "representatividade" ( $§ 2^{\circ}$ do art. $7^{\circ}$ da lei 9868/1999) exclui a possibilidade da pessoa natural ${ }^{9}$ ser reconhecida, formalmente, no controle objetivo de constitucionalidade como amicus curiae, nada obstando, porém, a apresentação de memoriais juntados por linha (Brandeis-Brief).

Além da concepção apresentada, verifica-se também que a admissão do amigo da Corte está atrelada à decisão discricionária do relator, sobre a qual, inicialmente, não caberia recurso, nos termos explícitos do $\S 2^{\circ}$ do art. $7^{\circ}$ da Lei $n^{\circ}$ 9868/1999.

Contudo, a jurisprudência do STF já se assentou no sentido de que, na busca pela representatividade adequada e pluralidade do debate constitucional, deve-se admitir a interposição de recurso de agravo de instrumento dirigido ao Plenário da Corte contra decisão do relator que negue a possibilidade de intervenção do amicus curiae (MELLO, 2012).

A justificativa jurisprudencial fundamenta-se na necessidade de maior abertura à pluralidade com o objetivo de atribuir validade estrutural democrática às decisões ofertada pelo STF em sede de controle concentrado de constitucionalidade, sem afastar o caráter informacional também atribuído ao instituto a auxiliar a Suprema Corte.

A admissão de recurso oferecido pelo amicus contra decisão da Suprema Corte é restritíssima em virtude da natureza não contenciosa, assim como sua natureza instrutória e informacional, condição que litiga contra sua legitimidade recursal (MEDINA, 2010, p. 78).

Outro motivo a litigar contra a ampliação recursal decorre do princípio da

\footnotetext{
${ }^{9}$ No MS n 32.033, o ministro relator Gilmar Mendes admitiu que pessoa natural, Senador da República Pedro Taques, ingressasse no feito na condição de amicus curiae, por não haver vedação legal, no controle concentrado e abstrato de constitucionalidade, não sendo ainda a via estreita do writ razão suficiente para afastar a possibilidade (MENDES, 2013). Tal posicionamento poderá auxiliar na evolução do próprio instituto e auxiliar na construção de novo viés cada vez mais amplo em sede de controle concentrado de constitucionalidade.
} 
exequibilidade processual $^{10}$, em que a eventual possibilidade poderia implicar em prejuízo à celeridade processual e comprometer a natureza jurídica do instituto.

Apesar das limitações apresentadas, a regulação da participação no processo de controle de constitucionalidade possibilitou ao amicus curiae sair do proscênio e apresentar-se formalmente como componente exógeno a influenciar interna e oficialmente a interpretação constitucional, sendo o instituto e as ampliações dirigidas a ele, sem dúvida, grande avanço em prol do reconhecimento de uma sociedade aberta aos intérpretes da Constituição, capazes de influir na escolha estatal.

A Suprema Corte brasileira, realizando leitura sistemática do ordenamento jurídico, avança no aperfeiçoamento do instituto, estabelecendo a ampliação gradativa da forma de atuação do amigo da Corte e da possibilidade de participação em geral, como se verificou na possibilidade de cooperação em audiência pública.

\section{Limitações à participação do amicus curiae incompatível com a validade estrutural democrática exigida pelo modelo de Estado Democrático de Direito}

Mesmo evidenciada a ampliação participativa do amicus curie no controle concentrado de constitucionalidade brasileiro, a legitimidade democrática necessária a estruturar as conclusões estatais exige o afastamento de barreiras subjetivas e discricionárias atualmente impostas pelo $\S 2^{\circ}$ do art. $7^{\circ}$ da Lei 9868/1999 impõem barreiras a construção compartilhada de decisões.

A limitação da participação do amicus curiae ao reconhecimento pelo relator acerca da "relevância da matéria e a representatividade" (BRASIL, 1999), constitui margem formal revestida de grande subjetividade que pode afastar mesmo aqueles que serão atingidos diretamente pela decisão, o que atentaria contra a cidadania, o direito à contínua contestação pública e à participação (DAHL, 2005, p. 26).

O posicionamento a validar o filtro, segundo o qual os destinatários das escolhas estatais, ainda que de forma reflexa, estão impedidos de participar da decisão a qual estarão submetidos é contrária à ideia de liberdade e atenta contra o modelo de Estado instituído pela Constituição de 1988.

O controle concentrado e abstrato de constitucionalidade, em virtude de seus efeitos,

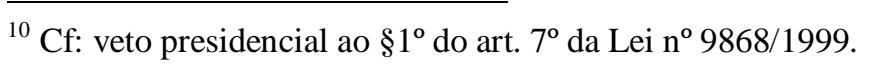




\section{A condição do amicus curiae no controle concentrado de constitucionalidade e o filtro a sua participação no modelo de estado brasileiro que se pretende democrático de direito}

é capaz de conduzir e direcionar programas executados, sendo, portanto extremamente amplo o número de atingidos por decisões judiciais, não se justificando a restrição à participação àqueles potencialmente atingidos, pois contrário ao modelo de Estado Democrático de Direito que exige a construção democrática de decisões como meio a estruturar validamente facticidades.

O STF vem adotando posicionamento ${ }^{11}$ segundo o qual, pessoa natural ou jurídica que possuam processos similares aos que aguardam julgamento de processo com repercussão geral reconhecida pela Corte, estão impedidos de atuar como amicus curiae no controle concentrado de constitucionalidade, justificando tal colocação em face da natureza objetiva da ação.

Contudo, não reconhecer o direito de participar daqueles que serão os destinatários diretos da decisão judicial parece afrontar frontalmente o modelo de Estado Democrático de Direito a que o art. $1^{\circ}$ caput da Constituição de 1988 declarou se Constitui a República brasileira.

A recognição restrita a parcela ínfima da população a influir nas decisões judiciais não se mostra adequadamente suficiente a representar as variedades interpretativas e a pluralidade social, mantendo a "grave questão pertinente à legitimidade democrática das decisões emanadas desta [pela] Corte, quando no desempenho de seu extraordinário poder de efetuar, em abstrato, o controle concentrado de constitucionalidade" (MELLO, 2013, p. 4), a qual o STF, conforme sua conveniência, declara pretender superar com o acolhimento formal de amici curiae.

Assim é possível afirmar que a Corte brasileira ora se mostra desejosa em reconhecer a sociedade abertura dos interpretes da Constituição, com a finalidade de superar seu reconhecido déficit democrático e voltado a estruturar validamente suas decisões, ora fixa posicionamento excludente àqueles diretamente atingidos pelas conclusões estatais.

A participação do amicus curiae, não reconhecido oficialmente, por meio de memoriais juntados por linha (Brandeis-Brief) compreende alternativa acatada pela Suprema Corte brasileira em superar o déficit democrático de suas decisões quando ela mesma se porta de formar refratária ao acolhimento oficial participativo.

A admissão de amicus curiae informalmente, apesar de se apresentar como

\footnotetext{
${ }^{11}$ Nesse sentido, as decisões monocráticas proferidas no RE 590880, Rel. Min. Rosa Weber, DJe 18.12.2012; RE 590.415, rel. Min. Joaquim Barbosa, DJe 04.10.2012, no RE 591.797-ED, rel. min. Dias Toffoli, DJe 08.4.2011, e no RE 576.155, rel. min. Ricardo Lewandowski, DJe 12.3.2009.
} 
alternativa para a participação reduz a capacidade de influência na decisão judicial, pois, não compondo oficialmente os autos, não estariam os julgadores atrelados ao enfretamento ou a observação das considerações propostas, retornando a figura do amigo da Corte à coxia, estabelecendo desigualdade de tratamento e níveis de influência entre aqueles que serão atingidos isonomicamente pela decisão judicial a ser proferida.

Mesmo admitindo a maior complexidade em procedimentos mais abertos, algo que poderia atentar contra o princípio da exequibilidade, a decisão judicial deve ser proferida em ambiente cercado de variações interpretativas, ainda que possam repercutir conflitos, pois gera conformidade diante do compromisso (konfliktund kompromissrecht) ajustado pelos envolvidos (HÄBERLE, 2002, p. 51), que, mesmo vencidos, passam a aceitar a interpretação fixada justamente porque o meio em que foi cunhada apresenta-se permeável a opiniões diversas (SARMENTO, 2012, p. 330).

Ademais, a conformidade decorrente da participação na tomada de decisões que estruturam democraticamente as opções interpretativas estatais colhidas, quando substancialmente observadas, atendendo aos preceitos do Estado Democrático de Direito em sua concepção forte, são revestidas de legitimidade a validar estruturalmente a coerção no Estado Democrático de Direito, devendo ser tão mais aberta quanto for o número de atingidos, não se justificando restrições fundadas em juiz discricionário, a depender da orientação adotada pelo ministro relator.

O caminho para se alcançarem escolhas democráticas é constante, e a Suprema Corte brasileira deve estar aberta às concepções pluralistas, não sendo honesta a postura que restringe a participação de maneira geral, abrindo possibilidades casuísticas, à livre escolha do julgador, conforme seu entendimento, momento ou assunto, o qual estaria disposto a aceitar a pluralidade social, apresentando-se como benevolente, quando o modelo de Estado declarado constitucionalmente exige como condição de validade e coerência com a estrutura jurídica criada em modelo de Estado Democrático de Direito que as decisões estatais estejam revestidas com o manto democrático participativo, como bem reconhece o STF quando lhe convém.

O reconhecimento da sociedade aberta aos intérpretes da Constituição não se dá de forma eventual, quando o relator admite a participação ao vislumbrar a necessidade de obtenção de apoio social, sendo necessário viver intensa e cotidianamente a democracia em sua vertente plural e o seu ideal direcionado à incansável ampliação participativa inclusiva, 


\section{A condição do amicus curiae no controle concentrado de constitucionalidade e o filtro a sua participação no modelo de estado brasileiro que se pretende democrático de direito}

dirigida, principalmente, àqueles potencialmente atingidos pelas escolhas estatais.

O Direito e seus critérios de validade sistêmicos restam condicionados à estrutura que lhes atribui legitimidade, o arcabouço que sustenta a facticidade imposta contra a liberdade quando desenvolvida em um Estado que se pretende democrático de direito exige ambiente amplamente democrático, potencialidade consistente na abertura plural e isonômica a influir nas escolhas direcionadas a coletividade, não sendo adequado o filtro contido no art. $7^{\circ}, \S 2^{\circ}$ da Lei $\mathrm{n}^{\mathrm{o}}$ 9868/1999 que condiciona a participação do amicus curiae à discricionariedade do relator, justamente por atentar contra o modelo de Estado declarado no art. $1^{\circ}$, caput, da Constituição da República de 1988.

\section{Conclusões}

O modelo de Estado brasileiro declarado no caput do art. $1^{\circ}$ da Constituição da República de 1988, Estado Democrático de Direito, exige que a formação das decisões estatais estejam prescindida formal e materialmente de aspectos democráticos.

A pós-modernidade, momento cercado de incertezas e inseguranças, constituído por sociedade plural e hipercomplexa não se satisfaz com a simples facticidade, exigindo como pressuposto à conformação participação direto dos potencialmente atingidos pela decisão.

Para que a efetiva participação voltada à construção decisória, capaz de gerar conformação, se opere é indispensável o reconhecimento de uma sociedade aberta dos interpretes, pois, a participação, não é elemento destinado apenas a conceder legitimidade, mas é elemento imprescindível a estruturar validamente as escolhas diante de percepções pluralistas sobre temas controvertidos.

O rol taxativo de legitimados a propor ações no controle concentrado de constitucionalidade, cujo resultado decisório é potencialmente vasto, atenta contra o modelo de Estado declarado Democrático de Direito quando restringe a participação dos potencialmente atingidos.

A possibilidade de participação formal e substancial de amici curiae no controle concentrado de constitucionalidade, apesar da existência de controvérsias sobre sua origem e conceito, nos EUA assim como no Brasil, exigem prerrequisitos que, por vezes, limitam ou dificultam a integração dos amigos da Corte.

Os filtros à participação do amicus curiae no controle de constitucionalidade 
brasileiro, fundados no princípio da exequibilidade, foram sendo relativizados, casuisticamente, desde sua regulação formal a partir da Lei nº 9868/1999, mantendo-se, entretanto a grande subjetividade e discricionariedade como elemento central à abertura.

Assim, a participação efetiva e formal do amicus curiae no controle de concentrado de constitucionalidade está restrita ao juízo de conveniência e oportunidade do relator, pois, reconhecendo a pertinência e adequação da participação tal decisão será irrecorrível, ou em caso negativo, mediante recurso de agravo de instrumento, o direito à participação formal poderá ser reconhecida pelo Plenário da Corte.

A participação do amicus curiae condicionada à discricionariedade acaba por afastar o instituto de sua função estrutural de validade e a conduz à condição instrumental utilizada pela Corte, conforme conveniência e oportunidade, a afastar o déficit democrático, nesse sentido o amigo da Corte se torna um instrumento a validar e não construir decisões estruturalmente válidas frente ao Estado que se pretende Democrático de Direito conforme a "benevolência" do relator ou do Plenário da Corte, como verdadeira exceção e não regra.

Portanto, é forçoso concluir que o filtro discricionário à participação do amicus curiae estabelecido pelo $\S 2^{\circ}$ do art. $7^{\circ}$ da Lei $n^{\circ}$ 9868/1999 é inadequado ao modelo de Estado Democrático de Direito quando não se voltar à estruturação válida da decisão estatal.

\section{Referências}

BRASIL. Constituição da República Federativa do Brasil, de 05 de outubro de 1988. Disponível em:

http://www.planalto.gov.br/ccivil 03/Constituicao/ConstituicaoCompilado.htm Acesso em: 21 mar. 2017.

BRASIL. Lei $n^{\circ}$ 4726, de 13 de julho de 1965. Disponível em: http://www.planalto.gov.br/ccivil_03/leis/1950-1969/L4726.htm. Acesso em: 21 mar. 2017. BRASIL. Lei $n^{\circ}$ 6385, de 7 de dezembro DE 1976. Disponível em: http://www.planalto.gov.br/ccivil 03/leis/L6385.htm. Acesso em: 21 mar. 2017. BRASIL. Lei $n^{\circ} 8884$, de 11 de junho de 1994. Disponível em: http://www.planalto.gov.br/ccivil 03/leis/L8884.htm. Acesso em: 21 mar. 2017. BRASIL. Lei $n^{\circ}$ 9.882, de 3 de dezembro de 1999. Disponível em: http://www.planalto.gov.br/ccivil_03/leis/19882.htm. Acesso em: 21 mar. 2017. BRASIL. Lei $n^{\circ}$ 9868, de 10 de novembro de 1999. Disponível em: http://www.planalto.gov.br/ccivil_03/leis/L9868.htm. Acesso em: 21 mar. 2017. BRASIL. Supremo Tribunal Federal. Regimento interno do Supremo Tribunal Federal. Brasília, jul. 2016. Disponível em: http://www.stf.jus.br/arquivo/cms/legislacaoRegimentoInterno/anexo/RISTF.pdf. Acesso em: 24 mar. 2017. 


\section{A condição do amicus curiae no controle concentrado de constitucionalidade e o filtro a sua participação no modelo de estado brasileiro que se pretende democrático de direito}

CANOTILHO, Joaquim José Gomes. Direito Constitucional e Teoria da Constituição. Coimbra: Almedina, 2003.

CARVALHO, Camilo de Oliveira. A função do amicus curiae no Estado Constitucional e Democrático de Direito. ENCONTRO NACIONAL DO CONPEDI/UFS. 20. 2012.

Uberlândia. Anais... Florianópolis, CONPEDI, p. 8831-8861, 2012.

COSTA, Alexandre Araújo; BENVINDO, Juliano Zaiden. A Quem Interessa o Controle Concentrado de Constitucionalidade? O Descompasso entre Teoria e Prática na Defesa dos Direitos Fundamentais. Brasília: Universidade de Brasília, 2013. Disponível em: http://www.ufjf.br/siddharta legale/files/2014/07/Alexandra-Costa-e-Juliano-Zaiden-a-queminteressa-o-controle.pdf. Acesso em: 21 mar. 2017.

DAHL, Robert A.. Poliarquia: participação e oposição. Trad. Celso Mauro Paciornik. São Paulo: Editora da Universidade de São Paulo, 2005.

HÄBERLE, Peter. Hermenêutica constitucional a sociedade aberta dos interpretes da Constituição: contribuição para a interpretação pluralista e "procedimental" da Constituição. Trad. Gilmar Ferreira Mendes. Porto Alegre: Sérgio Antônio Fabris Editor, 2002.

HABERMAS, Jürgen. Passado com futuro. Trad. Flávio Beno Siebeneichler. Rio de Janeiro: Tempo Brasileiro, 1993.

MEDINA, Damares. Amicus curiae: amigo da Corte ou amigo da parte? São Paulo: Saraiva, 2010.

MELLO, Celso de. Decisão monocrática proferida na Medida cautelar em Ação Direta de Inconstitucionalidade $n^{o}$ 5022, Brasília, 24 ago. 2013. Disponível em:

http://www.stf.jus.br/portal/processo/verProcessoPeca.asp?id=178764842\&tipoApp=.pdf. Acesso em: 18 set. 2016.

MELLO, Celso de. Voto no agravo regimental na ação direta de inconstitucionalidade $n^{o}$ 3396, Brasília, 30 abr. 2012. Disponível em:

http://www.stf.jus.br/portal/processo/verProcessoAndamento.asp?incidente=2268771. Acesso em: 21 mar. 2017.

MORAES, Anderson Júnio Leal. Audiências públicas como instrumento de legitimação da jurisdição constitucional. 119 f. Dissertação (Pós-graduação em Direito). Faculdade de Direito da Universidade Federal de Minas Gerais, Belo Horizonte, 2011.

RENATO HORTA, Rezende. A validade estrutural democrática das decisões no controle concentrado de constitucionalidade sobre política pública: abertura à interpretação constitucional. 190 f. Dissertação (Mestrado em Direito). Universidade Fumec, Belo Horizonte, 2017.

RENATO HORTA, R.; OLIVEIRA, A.; CAMPOS, F.; PAULA, V.; FANTONI, W.. O controle concentrado de constitucionalidade e a defesa de interesses corporativos: análise das ADIs no período de 2013 a 10 de novembro de 2015. Revista Digital Constituição e Garantia de Direitos (UFRN), Natal, v. 9, n. 2, p. 252-285, 2016.

SAMPAIO, José Adércio Leite. Teoria da constituição e dos direitos fundamentais. Belo Horizonte: Del Rey, 2013.

SARMENTO, Daniel. A dimensão objetiva dos direitos fundamentais: fragmentos de uma teoria. In: TORRES, Ricardo Lobo; MELO, Celso Albuquerque (Org.). Arquivos de direitos humanos. v. 4, Rio de Janeiro: Renovar, 2002.

UNITED STATES OF AMERICA. Supreme Court. Rules of the Court, of april 29, 2013. Disponível em: https://www.supremecourt.gov/ctrules/2013revisedrules.pdf. Acesso em: 21 mar. 2017.

VALLE, Regina Lírio do; VIEIRA, José Ribas; SILVA, Alfredo Canellas Guilherme da; SILVA, Cecília de Almeida; MOURA, Francisco; AJOUZ, Igor. Audiências públicas e 
ativismo: diálogo social no STF. Belo Horizonte: Fórum, 2012.

WEBER, Rosa. Despacho no Recurso Extraordinário no 592.891, proferida em 15 mai. 2012. Disponível em:

http://www.stf.jus.br/portal/processo/verProcessoTexto.asp?id=3132205\&tipoApp=RTF. Acesso em: 21 mar. 2017. 